(2) Open Access Full Text Article

\title{
Low uric acid is a risk factor in mild cognitive impairment
}

\author{
This article was published in the following Dove Press journal: \\ Neuropsychiatric Disease and Treatment \\ II September 2017 \\ Number of times this article has been viewed
}

\section{LingLing Xue \\ YongBing Liu \\ HuiPing Xue \\ Jin Xue \\ KaiXuan Sun \\ LinFeng Wu \\ Ping Hou}

School of Nursing, YangZhou

University, Yangzhou City, China
Correspondence: YongBing Liu School of Nursing, YangZhou University, No 88 South Road, Yangzhou City, Jiangsu Province, China Tel +86 I865230 I00। Email lyb|9950806@।26.com
Background: Mild cognitive impairment (MCI) represents a transitional stage between normal aging and dementia. Uric acid is a water-soluble antioxidant found in the body. Many recent studies have found that uric acid plays an important role in cognitive impairment, although the effects of uric acid on MCI are not clear.

Objective: The objective of this study was to explore the relationship between uric acid and MCI.

Methods: Using a random sampling method, this study investigated 58 patients with MCI and 57 healthy elderly from January 2016 to November 2016. Demographic information was collected, the subjects were evaluated using the Mini Mental Status Examination (MMSE), and uric acid was measured in fasting venous blood.

Results: A total of 57 (49.6\%) participants are healthy and 58 (50.4\%) participants had MCI. The uric acid level was significantly lower in the patients with MCI $(292.28 \pm 63.71 \mu \mathrm{mol} / \mathrm{L})$ than in the normal controls $(322.49 \pm 78.70 \mu \mathrm{mol} / \mathrm{L} ; P<0.05)$. There were significant positive correlations between the MMSE scores, for each dimension and the total score, and uric acid level (all $P<0.05$ ). Multivariate logistic regression models illustrated that uric acid was a protective factor for MCI (odds ratio $=0.999,95 \%$ CI $=0.987-0.999$ ).

Conclusion: A low uric acid level is a risk factor for MCI, and an appropriate increase in uric acid can be used to slow down the occurrence and development of MCI.

Keywords: mild cognitive impairment, uric acid, relationship

\section{Introduction}

Reisberg et al $^{1}$ first proposed that mild cognitive impairment (MCI) represents an intermediate stage between normal aging and dementia; the most important marker of MCI is cognitive impairment that is not sufficient to affect daily and social life. Petersen et $\mathrm{al}^{2}$ proposed the currently recognized diagnostic criteria for MCI: the patient complains of, or others confirm, memory impairment; objective tests show some cognitive change; and overall cognitive function and life ability are relatively normal, such that the patient cannot be diagnosed with dementia. Early intervention in MCI can slow down or prevent the development of dementia.

Uric acid, the final product of purine metabolism, is a water-soluble antioxidant that inhibits nitrite-mediated nitrification, ${ }^{3}$ binds to iron, and inhibits the oxidative damage caused by iron-dependent ascorbate oxidation. ${ }^{4}$ Over a range of values, uric acid has antioxidant properties; when it exceeds this range, it becomes a pro-oxidative agent and can cause gout, hypertension, and kidney and cardiovascular diseases. ${ }^{5}$

Increasing numbers of studies have found that uric acid plays an important role in cognitive impairment. ${ }^{6-10}$ A relationship between uric acid and cognitive function has been demonstrated, and studies have investigated the association between uric acid 
and cognitive dysfunction in the context-specific diseases and various types of dementia. However, the relationship between uric acid and MCI has seldom been studied.

\section{Objectives and methods Subjects \\ Sample selection}

A random sampling survey method was used to identify elderly research subjects in Northern Jiangsu People's Hospital from January 2016 to November 2016. Those who met the diagnostic criteria for MCI in the elderly ( $>60$ years of age) constituted the MCI group, and age- and sex-matched individuals were recruited to the normal control group.

\section{Inclusion criteria}

1) Self-perception of memory loss or memory impairment reported by close acquaintances time $<3$ months; 2) Mini Mental Status Examination (MMSE) score $\leq 26 ; 3$ ) Global Deterioration Scale (GDS) score of 2 or 3; 4) total Activity of Daily Living Scale (ADL) score $<16 ; 5$ ) does not meet the diagnostic criteria for dementia; and 6) provided informed consent.

\section{Exclusion criteria}

1) Blindness, deafness, or difficulty with verbal expression;

2) schizophrenia, affective disorder, organic mental disorders, mental retardation, or similar diagnoses; 3) Alzheimer's disease (AD), vascular dementia, Parkinson's disease dementia, or organic brain disease causing dementia; 4) Hamilton Depression Scale score indicating depression and anxiety caused by pseudo-dementia; 5) taking drugs that affect the level of uric acid, such as aspirin, penicillin, and so on; and 6) refusal to provide informed consent.

\section{Methods}

\section{Cognitive function monitoring}

The MMSE and GDS were used to quantify cognitive dysfunction. A face-to-face interview with each participant was conducted by a trained investigator. The MMSE is an influential cognitive function screening tool designed by Folstein et al. ${ }^{11}$ It evaluates 11 parts, including orientation, memory, computation, language, visual space, the five dimensions with a maximum score of 30 points. The MMSE scale is widely used in cognitive function testing, and studies have shown that it detects dementia with a sensitivity of $0.8-0.9$ and specificity of $0.7-0.8$. However, the MMSE lacks good sensitivity and specificity for evaluating mild dementia in patients with higher education or MCI patients with cognitive function. ${ }^{12}$ Therefore, we used the GDS to assist in the diagnosis. According to "China's prevention and treatment of cognitive dysfunction experts consensus," a GDS score of 2 or 3 together with an MMSE score of at least 24 points is not sufficient for a diagnosis of dementia.

\section{Uric acid test}

After fasting overnight, $3 \mathrm{~mL}$ venous blood was obtained to measure the serum uric acid level within 30 minutes, using an enzyme-labeled method on a Hitachi 7170 automatic biochemical analyser (Hitachi, Tokyo, Japan).

The present study was performed in accordance with the Declaration of Helsinki, and the study protocol was approved by the Ethics Committee of Northern Jiangsu People's Hospital.

\section{Data analysis}

A database was constructed using EpiData 3.1 software (EpiData Association, Odense, Denmark) with double entry of data. The data were analyzed using SPSS software (ver 16.0; SPSS Inc., Chicago, IL, USA). Continuous variables were expressed as means and $\mathrm{SD}$, accompanied by rates or ratios. The two groups were compared using the $t$-test. The correlation between MMSE score and uric acid level was analyzed using Pearson correlation. A binary logistic regression model was used for multivariate analysis. A difference of $P<0.05$ was deemed statistically significant.

\section{Results}

After cognitive testing, the participants were divided into $\operatorname{MCI}(n=58)$ and healthy control groups $(n=57)$. Two subjects with dementia, three with other mental problems, and five with gout were excluded.

\section{Demographic characteristics}

Table 1 shows the characteristics of the two groups. The mean age of the MCI group and healthy controls was $68.21 \pm 4.49$

Table I Demographic characteristics of the $\mathrm{MCl}$ and healthy control groups

\begin{tabular}{|c|c|c|c|c|}
\hline $\begin{array}{l}\text { Demographic } \\
\text { characteristics }\end{array}$ & $\begin{array}{l}\mathrm{MCl} \text { group } \\
(\mathrm{n}=58)\end{array}$ & $\begin{array}{l}\text { Healthy controls } \\
(n=57)\end{array}$ & $t$ & $P$-value \\
\hline Age (years) & $68.21 \pm 4.49$ & $68.32 \pm 5.87$ & 0.075 & 0.940 \\
\hline Sex & & & & 0.911 \\
\hline Male (n) & 36 & 34 & 0.112 & \\
\hline Female (n) & 22 & 23 & & \\
\hline Years of education & & & & $<0.0$ I \\
\hline Illiterate (n) & 10 & 2 & 3.168 & \\
\hline $\begin{array}{l}\text { Primary school- } \\
\text { educated }(n)\end{array}$ & 29 & 20 & & \\
\hline $\begin{array}{l}\text { Junior high school } \\
\text { and above }(n)\end{array}$ & 19 & 35 & & \\
\hline
\end{tabular}

Abbreviation: $\mathrm{MCl}$, mild cognitive impairment. 
Table 2 Univariate analysis of cognitive impairment (continuous variables)

\begin{tabular}{lllll}
\hline Characteristic & $\begin{array}{l}\text { MCl group } \\
(\mathbf{m e a n} \pm \mathbf{S D})\end{array}$ & $\begin{array}{l}\text { Healthy } \\
\text { controls }\end{array}$ & $\boldsymbol{t}$ & P-value \\
\hline Age (years) & $68.21 \pm 4.49$ & $68.32 \pm 5.87$ & 0.112 & $0.91 \mathrm{I}$ \\
Height $(\mathrm{cm})$ & $166.83 \pm 7.55$ & $167.28 \pm 9.35$ & 0.286 & 0.776 \\
Weight $(\mathrm{kg})$ & $60.93 \pm 10.06$ & $67.01 \pm 10.85$ & 3.113 & $<0.01$ \\
BMI $\left(\mathrm{kg} / \mathrm{m}^{2}\right)$ & $21.89 \pm 3.20$ & $23.87 \pm 2.72$ & 3.565 & $<0.01$ \\
MMSE score & $23.91 \pm 2.07$ & $28.11 \pm 1.03$ & 13.776 & $<0.01$ \\
Uric acid $(\mu \mathrm{mol} / \mathrm{L})$ & $292.28 \pm 63.71$ & $322.49 \pm 78.70$ & 2.261 & 0.026 \\
\hline
\end{tabular}

Abbreviations: BMI, body mass index; $\mathrm{MCl}$, mild cognitive impairment; MMSE, Mini-Mental State Examination.

and $68.32 \pm 5.87$ years, respectively (range: $60-85$ years). The MCI group included 36 males (62.1\%) and 22 females (37.9\%) and the healthy controls comprised 34 males (59.6\%) and 23 females (40.4\%). Regarding the level of education, the MCI group comprised 10 illiterate patients (17.2\%), 29 with primary school education (50\%), and 19 with junior middle school education or above (32.8\%); the respective numbers of healthy controls were $2(3.5 \%), 20(35.1 \%)$, and $35(61.4 \%)$. There were no significant differences in age or sex between the MCI and healthy control groups, while there was a significant difference in years of education (Table 1).

\section{Differences between the two groups}

Table 2 shows the differences in continuous variables between the two groups. Weight, body mass index, MMSE score, and uric acid differed significantly between the two groups, with $P=0.002,0.001,0.000$, and 0.026 , respectively.

Table 3 shows the differences in categorical variables between the two groups revealed by the $t$-test. Smoking (yes or no), alcoholism (yes or no), diabetes (yes or no), hypertension

Table 3 Additional disease information for the two $\mathrm{MCl}$ and healthy control groups

\begin{tabular}{|c|c|c|c|c|}
\hline Disease & $\begin{array}{l}\text { MCl Group } \\
\text { (N) }\end{array}$ & $\begin{array}{l}\text { Healthy } \\
\text { controls }(\mathrm{N})\end{array}$ & $t$ & $P$-value \\
\hline \multicolumn{4}{|l|}{ Smoking } & 0.014 \\
\hline Yes & 22 & 10 & 2.488 & \\
\hline No & 36 & 47 & & \\
\hline \multicolumn{4}{|c|}{ Alcoholism } & 0.048 \\
\hline Yes & 25 & 12 & 2.003 & \\
\hline No & 33 & 45 & & \\
\hline \multicolumn{4}{|l|}{ Diabetes } & 0.005 \\
\hline Yes & 17 & 5 & 2.886 & \\
\hline No & 41 & 52 & & \\
\hline \multicolumn{4}{|c|}{ Hypertension } & 0.001 \\
\hline Yes & 24 & 8 & 3.415 & \\
\hline No & 34 & 49 & & \\
\hline \multicolumn{4}{|c|}{ Family history of dementia } & 0.011 \\
\hline Yes & 14 & 4 & 2.588 & \\
\hline No & 44 & 53 & & \\
\hline
\end{tabular}

Abbreviation: $\mathrm{MCl}$, mild cognitive impairment.
Table 4 Correlation between MMSE score and uric acid

\begin{tabular}{|c|c|c|c|c|c|}
\hline \multicolumn{2}{|c|}{ Orientation } & Memory & Computation & Language & $\begin{array}{l}\text { Visual } \\
\text { space }\end{array}$ \\
\hline \multicolumn{6}{|c|}{$\mathrm{MCl}$ group } \\
\hline$r$ & 0.473 & 0.635 & 0.564 & 0.357 & 0.421 \\
\hline$P$ & $<0.001$ & $<0.001$ & $<0.001$ & $<0.001$ & $<0.001$ \\
\hline \multicolumn{6}{|c|}{ Healthy controls } \\
\hline$r$ & 0.498 & 0.685 & 0.572 & 0.402 & 0.469 \\
\hline$P$ & $<0.001$ & $<0.001$ & $<0.001$ & $<0.00$ I & $<0.00$ I \\
\hline
\end{tabular}

(yes or no), and family history of dementia (yes or no) statuses were significantly different between the two groups ( $P=0.014,0.048,0.005,0.001$, and 0.011 , respectively).

\section{Correlation between uric acid and MMSE score by Pearson correlation}

There were significant positive correlations between MMSE score and uric acid, including orientation, memory, computation, language, and visual space five dimensions $(P<0.05)$. Similarly, in the normal control group also, there was a significant positive correlation $(P<0.05)$ (Table 4$)$.

\section{Possible factors associated with $\mathrm{MCl}$ in multivariate logistic regression models}

Smoking (yes or no), alcoholism (yes or no), diabetes (yes or no), and hypertension (yes or no) statuses, as well as age, sex, education, MMSE score, height, weight, and uric acid level, were included in the multivariate logistic regression models. We found that uric acid level (odds ratio $=0.999,95 \%$ confidence interval: 0.988-1.000) might contribute to MCI (Table 5).

\section{Discussion}

The incidence of MCI is increasing, with studies showing that the prevalence is as high as $20 \%$ in people older than 60 years of age $;^{13}$ such people will soon progress to dementia. ${ }^{14}$ Several studies have explored the risk factors for MCI.${ }^{15-17}$ One study reported that $52.8 \%$ of MCI patients had physical illnesses ${ }^{18}$ which were risk factors for worsening cognitive function. To prevent or delay the development of dementia in the early stages, interventions should be carried out in MCI populations.

Table 5 Relationship between uric acid and cognition

\begin{tabular}{|c|c|c|c|c|c|c|c|}
\hline Factor & B & SE & Wald & $d f$ & $P$-value & OR & $95 \% \mathrm{Cl}$ \\
\hline Uric acid & 0.006 & 0.003 & 4.684 & I & 0.03 & 0.999 & $0.987-0.999$ \\
\hline
\end{tabular}
standard error; Wald, Chi-square value. 
Few studies have examined the association between uric acid and cognitive status, ${ }^{19,20}$ especially MCI. The impact of a small sample size on any such association remains controversial, and age, sex, and other factors may also have an impact. Although uric acid is an antioxidant, it has prooxidation characteristics under certain conditions. One study showed that high blood uric acid levels can lead to a microinflammatory state and produce oxidative stress, resulting in microvascular disease, arteriolar hyalinization, sever arteriosclerosis, increased cerebral ischemia, and hypoxia, increasing the risk of cognitive impairment. ${ }^{21}$ Although the results of that study did not match our findings, it included patients with cardiovascular disease, for which uric acid is a risk factor. ${ }^{22-24}$ Other studies found that low levels of uric acid were associated with cognitive impairment, ${ }^{25,26}$ consistent with our results. Our study found that the uric acid level was significantly lower in patients with MCI $(292.28 \pm 63.71 \mu \mathrm{mol} / \mathrm{L})$ than in the normal controls (322.49 $\pm 78.70 \mu \mathrm{mol} / \mathrm{L} ; P<0.05)$.

Patients with MCI are at high risk of developing dementia, ${ }^{27}$ but early and effective interventions can reduce the risk. ${ }^{28}$ Further research on the association between uric acid level and MCI may facilitate the development of effective and early interventions for patients with MCI. Future research should examine whether there is a reasonable range of uric acid values that does not induce dementia or cause cardiovascular or metabolic diseases.

\section{Limitations}

There are some limitations in our study. First, the sample content was finite. Second, we collected only the information on whether the subjects had diabetes or hypertension but we did not gather the information about detailed medication. Third, the research was only a cross-sectional study, we could not define the long-term effects of uric acid on cognitive function.

\section{Conclusion}

A low uric acid level is a risk factor for MCI, and an appropriate increase in uric acid can be used to slow down the occurrence and development of MCI.

\section{Disclosure}

The authors report no conflicts of interest in this work.

\section{References}

1. Reisberg B, Ferris SH, de Leon MJ, Crook T. The Global Deterioration Scale for assessment of primary degenerative dementia. Am J Psychiatry. 1982;139(9):1136-1139.
2. Petersen RC, Smith GE, Waring SC, Ivnik RJ, Tangalos EG, Kokmen E. Mild cognitive impairment: clinical characterization and outcome. Arch Neurol. 1999;56(3):303-308.

3. Hooper DC, Scott GS, Zborek A, et al. Uric acid, a peroxynitrite scavenger, inhibits CNS inflammation, blood-CNS barrier permeability changes, and tissue damage in a mouse model of multiple sclerosis. FASEB J. 2000;14(5):691-698.

4. Kim TS, Pae CU, Yoon SJ, et al. Decreased plasma antioxidants in patients with Alzheimer's disease. Int J Geriatr Psychiatry. 2006;21(4): 344-348.

5. Davies KJA, Sevanian A, Muakkassah-Kelly SF, Hochstein P. Uric acid-iron ion complexes. A new aspect of the antioxidant functions of uric acid. Biochem J. 1986;235(3):747-754.

6. $\mathrm{Du} \mathrm{N}, \mathrm{Xu} \mathrm{D}, \mathrm{Hou} \mathrm{X}$, et al. Inverse association between serum uric acid levels and Alzheimer's disease risk. Mol Neurobiol. 2015;53(4): 2594-2599.

7. Lieberman A. Are dementia and depression in Parkinson's disease related? J Neurol Sci. 2006;248(1):138-142.

8. Weisskopf MG, O'Reilly E, Chen H, Schwarzschild MA, Ascherio A. Plasma urate and risk of Parkinson's disease. Am J Epidemiol. 2007; 166(5):561-567.

9. Shen L, Ji HF. Low uric acid levels in patients with Parkinson's disease: evidence from meta-analysis. BMJ. 2013;3(11):e003620.

10. Annanmaki T, Pohja M, Parviainen T, Hakkinen P, Murros K. Uric acid and cognition in Parkinson's disease: a follow-up study. Parkinsonism Relat Disord. 2011;17(5):333-337.

11. Folstein MF, Folstein SE, McHugh PR. "Mini-mental state": a practical method for grading the cognitive state of patients for the clinician. J Psychiatric Res. 1975;12(3):189-198.

12. Scazufca M, Almeida OP, Vallada HP, Tasse WA, Menezes PR. Limitations of the Mini-Mental State Examination for screening dementia in a community with low socioeconomic status. Eur Arch Psychiatry Clin Neurosci. 2009;259(1):8-15.

13. Petersen RC. Mild cognitive impairment. Continuum. 2016; 22(2 Dementia):404-418.

14. Chen TF, Lin CC, Chen YF, et al. Diffusion tensor changes in patients with amnesic mild cognitive impairment and various dementias. Psychiatry Res. 2009;173(1):15-21.

15. Kida J, Nemoto K, Ikejima C, et al. Impact of depressive symptoms on conversion from mild cognitive impairment subtypes to Alzheimer's disease: a community-based longitudinal study. J Alzheimer's Dis. 2016; 51(2):405-415.

16. Ansari Z. Homocysteine and mild cognitive impairment: are these the tools for early intervention in the dementia spectrum? J Nutr Health Aging. 2016;20(2):155-160.

17. Gao Y, Xiao Y, Miao R, et al. The prevalence of mild cognitive impairment with type 2 diabetes mellitus among elderly people in China: a cross-sectional study. Arch Gerontol Geriatr. 2016;62:138-142.

18. Gu XL, Fei WM, Wang YM, et al. Investigation and analysis of community senior citizens with mild cognitive impairment. Zhonghua Yi Xue Shi Jian Za Zhi. 2008;7(3):206-208.

19. Annanmaki T, Pessala-Driver A, Hokkanen L, Murros K. Uric acid associates with cognition in Parkinson's disease. Parkinsonism Relat Disord. 2008;14(7):576-578.

20. Schretlen DJ, Inscore AB, Jinnah HA, et al. Serum uric acid and cognitive function in community-dwelling older adults. Neuropsychology. 2007;21(1):136.

21. Perna L, Mons U, Schöttker B, et al. Association of cognitive function and serum uric acid: are cardiovascular diseases a mediator among women? Exp Gerontol. 2016;81:37-41.

22. Weir CJ, Muir SW, Walters MR, Lees KR. Serum urate as an independent predictor of poor outcome and future vascular events after acute stroke. Stroke. 2003;34(8):1951-1956.

23. Schretlen DJ, Inscore AB, Vannorsdall TD, et al. Serum uric acid and brain ischemia in normal elderly adults. Neurology. 2007;69(14): $1418-1423$. 
24. Vannorsdall TD, Jinnah HA, Gordon B, Kraut M, Schretlen DJ. Cerebral ischemia mediates the effect of serum uric acid on cognitive function. Stroke. 2008;39(12):3418-3420.

25. Rinaldi P, Polidori MC, Metastasio A, et al. Plasma antioxidants are similarly depleted in mild cognitive impairment and in Alzheimer's disease. Neurobiol Aging. 2003;24(7):915-919.

26. Cao B, Wei QQ, Ou R, Yang J, Shang HF. Association of serum uric acid level with cognitive function among patients with multiple system atrophy. J Neurol Sci. 2015;359(1):363-366.
27. Hänninen T, Hallikainen M, Tuomainen S, Vanhanen M, Soininen H. Prevalence of mild cognitive impairment: a population - based study in elderly subjects. Acta Neurologica Scand. 2002;106(3):148-154.

28. Forstmeier S, Maercker A. Motivational processes in mild cognitive impairment and Alzheimer's disease: results from the Motivational Reserve in Alzheimer's (MoReA) study. BMC Psychiatry. 2015;15(1):1.

\section{Publish your work in this journal}

Neuropsychiatric Disease and Treatment is an international, peerreviewed journal of clinical therapeutics and pharmacology focusing on concise rapid reporting of clinical or pre-clinical studies on a range of neuropsychiatric and neurological disorders. This journal is indexed on PubMed Central, the 'PsycINFO' database and CAS, and is the official journal of The International Neuropsychiatric Association (INA). The manuscript management system is completely online and includes a very quick and fair peer-review system, which is all easy to use. Visit http://www.dovepress.com/testimonials.php to read real quotes from published authors.

Submit your manuscript here: http://www.dovepress.com/neuropsychiatric-disease-and-treatment-journal 